\title{
STRUCTURAL BRAIN ABNORMALITIES IN EARLY-ONSET SCHIZOPHRENIA
}

\author{
Maria Cristina Lombardo Ferrari', Luci Kimura², Luciana M. Nita², Hélio Elkis ${ }^{3}$
}

\begin{abstract}
Background: Few studies investigated brain abnormalities in early onset schizophrenia. Objective: To assess computed tomography (CT) abnormalities in patients with childhood or adolescence onset schizophrenia. Method: $\mathrm{CT}$ scans of patients with childhood (6 to 11 years old) (N=6) or adolescence (12-17 years old) $(\mathrm{N}=9)$ schizophrenia were compared to normal controls. Patients were diagnosed based on the DSM-III-R criteria. Ventricular enlargement was measured by the Ventricle to Brain Ratio (VBR) and Cortical Atrophy (pre-frontal prominence) was measured by the Pre-Frontal Atrophy Index (PFAI). Results: There was a significant difference in VBR, but not in PFAl, between subjects and controls [8.26 \pm 2.79 , and $5.71 \pm 3.26(p=0.029)]$, and $[2.72 \pm 1.77$, and $3.21 \pm 1.53(p=0.424)]$, respectively. There were no differences of VBR and PFAI between children and adolescents with schizophrenia. Conclusion: Compared to controls, patients with child or adolescent onset schizophrenia exhibit more pronounced ventricular enlargement. There were no differences regarding prefrontal atrophy.
\end{abstract}

KEY WORDS: schizophrenia, early-onset schizophrenia, computed tomography.

\begin{abstract}
Anormalidades estruturais cerebrais em esquizofrenia de início precoce
RESUMO - Introdução: Poucos estudos investigaram anormalidades cerebrais em esquizofrenia de início precoce. Objetivo: Avaliar anormalidades cerebrais em tomografias computadorizadas (TC) em pacientes com esquizofrenia de início precoce. Método: Foram comparadas TCs de pacientes com esquizofrenia de início na infância (6-11 anos de idade) ( $\mathrm{N}=6)$ e na adolescência (12-17 anos de idade) ( $\mathrm{N}=9$ ). $\mathrm{O}$ diagnóstico foi feito de acordo com os critérios do DSM-III-R. A dilatação ventricular foi medida pela Razão VentricularCerebral (VBR) e a atrofia cortical (avaliação da proeminência pré-frontal), pelo Índice de Atrofia PréFrontal (PFAl). Resultados: Houve uma diferença do VBR, mas não do PFAl, entre pacientes e controles $[8,26 \pm 2.79$, e $5,71 \pm 3,26(p=0,029)$, e $[2,72 \pm 1,77$, e $3,21 \pm 1,53(p=0,424)]$. A comparação entre crianças e adolescentes com esquizofrenia não revelou diferenças nestes parâmetros. Conclusão: Comparados aos controles, pacientes com esquizofrenia de início precoce na infância ou adolescência apresentam dilatação ventricular mais pronunciada. Nao houve diferenças em relação à atrofia pré-frontal.
\end{abstract}

PALAVRAS-CHAVE: esquizofrenia, esquizofrenia de início precoce, tomografia computadorizada.

Child or adolescent-onset schizophrenia (early onset schizophrenia - EOS), is not a distinct psychotic disorder, according to the Diagnostic and Statistic Manual for Mental Disorders - $4^{\text {th }}$ edition (DSM-IV) ${ }^{1}$ or to the International Classification of Diseases - $10^{\text {th }}$ edition (ICD-10)2. However, Kraepelin have early observed that symptoms of dementia praecox were present since childhood ${ }^{3}$. There are few epidemiological data on the prevalence of EOS, but the estimated prevalence is approximately $1 / 10000$ inhabitants 4 . Age of onset below 12 years old is considered rare ${ }^{5}$.
Some authors have reported a prevalence of 0.20 to 0.47 per 1000 children below 5 years old 6 . EOS is believed to be much less prevalent than autism ${ }^{7}$ but may provide a model for the comprehension of the pathogenesis of the schizophrenia, specially in terms of the neurodevelopmental hypothesis ${ }^{5}$. Schizophrenic children and adolescent, although clinically similar to patients with later onset schizophrenia ${ }^{8}$ have more pre-morbid changes ${ }^{9}$ along with a more chronic course of the disease ${ }^{10}$, possibly due to more severe genetic alterations leading to greater neurodevel-

\footnotetext{
${ }^{1} \mathrm{MD}, \mathrm{PhD}$, Instituto de Psiquiatria, Hospital das Clínicas, Faculdade de Medicina, Universidade de São Paulo, São Paulo SP, Brazil (HC/FMUSP); ${ }^{2}$ MD, HC/FMUSP; ${ }^{3}$ MD, PhD, Departamento e Instituto de Psiquiatria, FMUSP. At the time of data collection, Dr. Luci Kimura and Dr. Luciana M. Nita received FAPESP undergraduate scientific training grants (numbers 97/11022-0 and 97/13958-3, respectively).
}

Received 15 December 2005, received in final form 19 May 2006. Accepted 17 June 2006.

Dr. Helio Elkis - Instituto de Psiquiatria - HC - FMUSP - Rua Ovidio Pires de Campos 785 - $05403-010$ - São Paulo SP - Brasil. E-mail: helkis@usp.br 
opment damage. Several authors have reported brain abnormalities among adult schizophrenic patients, such as reduction in the medial temporal lobe, lateral and third ventricle enlargement, lower brain volume, basal ganglia enlargement and thalamic abnormalities ${ }^{7}$. Among them lateral ventricle enlargement is by far the most replicated finding ${ }^{11}$; however, there are scant data on neuroimaging abnormalities among children and adolescents with schizophrenia, with few controlled studies.

In terms of computed assisted tomography (CT scan) studies, Schulz et al. ${ }^{12}$ have compared computed tomography (CT) scans of 15 adolescents with schizophreniform disorder and schizophrenia, with normal subjects, and found a significant lateral ventricular enlargement (LVE) in those subjects with schizophrenia. These authors have also observed that the degree of LVE did not correlate with illness duration. In a comparative study between children with schizophrenia or schizotypal personality disorder, and controls, Reiss et al. ${ }^{13}$ also observed a greater frequency of LVE in patients than controls. Recently, Badura et al. ${ }^{14}$ compared CT scans of 19 patients with EOS with controls and found that ventricular enlargement in patients showed a trend to be larger in the patient's group. Longitudinal magnetic resonance imaging (MRI) studies in child and adolescent onset schizophrenia have contributed for more accurately testing the neurodevelopmental hypothesis of schizophrenia, showing that gray matter reduction, ventricular enlargement and reduction of then hippocampal volume appear to be an exaggeration of the normal cortical development due the pathogenesis of the disorder ${ }^{15}$. In terms of the relationship between brain abnormalities and the three psychopathological syndromes or dimensions of schizophrenia ${ }^{16}$ [positive (delusions and hallucinations), negative (alogia, flattening of affect, avolition), and disorganization] some studies showed that the positive symptoms are related to normal ventricles, while the negative symptoms are related to enlarged ventricles ${ }^{17}$ and reduced brain volume ${ }^{18}$ whereas other studies have found an association between the onset of deficits during childhood and brain structural abnormalities ${ }^{10,18}$ as well as negative symptoms and neuropsychological deficits $^{19}$. Such studies found that children with schizophrenia present a higher frequency of negative symptoms, and, more often, a poorer prognosis.

The aim of the present study is the investigation of brain abnormalities in children or adolescents with schizophrenia by CT scans, especially in terms of ven- tricular enlargement which, as previously mentioned, is considered to be the most consistent finding, either in childhood onset or adult onset schizophrenia ${ }^{15}$.

\section{METHOD}

This research was performed at the Child and Adolescent Psychiatry Unit of the Institute of Psychiatry - School of Medicine - University of São Paulo, in São Paulo, Brazil, between 1995 and 1997. Fifteen patients diagnosed with schizophrenia according to DSM-III-R criteria ${ }^{20}$ (which were the current criteria during the data collection), aged between 6 and 17 years old were included in the study. The local ethical committee approved the protocol.

Inclusion criteria consisted of age of onset of the disorder between 6 and 17 years-old. Psychotic organic disorders, history of seizures, history of treatment with corticosteroids, drug or alcohol use, and proven mental retardation prior to symptom onset, were exclusion criteria. The control group included patients without schizophrenia, who were within the same age range as subjects, and were submitted to CT scans due to other medical problems, as for example as headache or trauma.

Subjects were diagnosed with schizophrenia by the DSM-III-R criteria based on a semi-structured interview, the Schedule for Affective Disorders and Schizophrenia for School-Age Children, Present Version (KSADS-P) ${ }^{21}$. The Schedule for Affective Disorders and Schizophrenia for SchoolAge Children Epidemiologic Version (KSADS-E) ${ }^{22}$ was used to assess severity of symptoms. The interviewers were experienced psychiatrists with specific training on these instruments.

Positive symptoms were considered the sum of KSADS$P$ scores for delusions and hallucinations, whereas negative symptoms were considered the sum of KSADS-P scores for affective blunting, volition and poverty of content. Disorganization was taken as the sum of KSAPDS-P scores for incoherence, weird speech, bizarre behavior, and affective disagreement.

Subjects were divided into two groups: child-onset schizophrenia (6 to 11 years old) $(\mathrm{N}=6)$, and adolescent-onset schizophrenia (12-17 years old) $(\mathrm{N}=9)$. Both study and control groups were compared in terms of CT findings.

CT scans were obtained at the Neuroradiology Unit of Hospital das Clínicas - School of Medicine - University of São Paulo, in São Paulo, Brazil. A high resolution (160x160), 120 KV, 100 mA Pace-Plus (General Electric) device was used. Slices of $10 \mathrm{~mm}$ in thickness were taken from the orbitomeatal ascending line, from the skull base to vertix, with an average exposure time of 2 seconds. The neuroimaging parameters used to compare groups were the VentricleBrain Ratio (VBR), and the Pre-Frontal Atrophy Index (PFAI).

VBR represents the ratio between brain ventricle and total brain areas. The VBR was based on the Synek and Reuben method ${ }^{23}$, modified by Shelton et al. ${ }^{24}$, with measurements performed on slices in which the lateral ventricle body was most prominent. The areas of the left and right 
bodies of the lateral ventricles were measured 10 times and averaged. The whole brain area was measured once. The left and right ventricular body measurements were added together, divided by the total brain area, and multiplied by 100 to give the VBR measurement. Cortical atrophy was assessed by the liquor-filled pre-frontal space known as PFA Index ${ }^{25,26}$ (PFAl) which represents the enlargement of presulcal frontal prominence. The PFAI was measured by degree of discontinuity of the brain, related to the bone table of the frontal region between Sylvian fissures on the slice in which the Monro foramen was best observed. The goal was to measure the number of millimeters of gyral surface pulled away from the skull. Next, the total number of $\mathrm{mm}$ of gyral surface (from all frontal gyri) pulled away (discontinuous) from the skull was summed. Finally, the percentage of the total curved circumference of the frontal cortex that was discontinuous to the gyral surface was computed.

Two raters evaluated independently the radiographic films and images were transferred to a computer. VBR and PFAl measurements were obtained using the free software "Image Tool for Windows, version 1.28" obtained through the internet (www.nih.gov).

The inter rater reliability was measured by the Intraclass Correlation Coefficient ${ }^{27}$. Due to the small sample size and non normal distribution of most variables a non- parametric statistical approach was chosen. Dichotomous variables were analyzed by the chi-square or Fischer's tests. Continuous variables (means and standard deviations) were compared using the Mann-Whitney $U$ test. Spearman correlation coefficients (Rho) were used to correlate neuroimaging parameters with demographic and psychopathological variables. The correlation's significance values were corrected by the Bonferroni method. The Statistical Package for Social Sciences (SPSS) for Windows version 12.0 was used, all tests were two-tailed and the level of significance of 0.05 was adopted.

\section{RESULTS}

At the time of the neuroimaging study, the mean \pm s.d. age of the whole sample (including patients and controls) was $13.3 \pm 2.94$ years old, and the age of onset of the disorder was $10.67 \pm 3.58$ years, and the duration of illness was $2.93 \pm 1.22$ years. Patients had a mean age of $13.6 \pm 3.4$ years, and controls had a mean age of $13 \pm 2.48$ years old. There were 6 boys and 9 girls in the control group, and 9 boys and 6 girls in patients group. There were no differences between

Table 1. VBR and PFAl: comparison of the whole sample of patients with early onset schizophrenia versus controls.

\begin{tabular}{lllccc}
\hline Measurement & Groups & $\mathrm{N}$ & Mean & Standard deviation & $\mathrm{U}(\mathrm{p})$ \\
\hline VBR & Patients & 15 & 8.26 & 2.80 & $62(0.036)$ \\
& Controls & 15 & 5.70 & 3.30 & \\
PFAI & Patients & 15 & 2.72 & 1.78 & $87(0.29)$ \\
& Controls & 15 & 3.21 & 1.53 & \\
\hline
\end{tabular}

VBR, ventricle to brain ratio; PFAl, pre-frontal sulcal prominence index; U, Mann-Whitney test; $p$, significance.

Table 2. VBR and PFAl: comparisons between patients with children or adolescent onset schizophrenia and normal controls.

\begin{tabular}{|c|c|c|c|c|c|}
\hline & & $\mathrm{N}$ & Mean & Standard deviation & $U(p)$ \\
\hline \multicolumn{6}{|c|}{ Child-onset schizophrenia } \\
\hline \multirow[t]{2}{*}{ VBR } & Patients & 6 & 8.31 & \pm 3.21 & $11(0.262)$ \\
\hline & Controls & 6 & 5.82 & \pm 2.51 & \\
\hline \multirow[t]{2}{*}{ PFAI } & Patients & 6 & 1.92 & \pm 1.02 & $11(0.262)$ \\
\hline & Controls & 6 & 3.14 & \pm 1.93 & \\
\hline \multicolumn{6}{|c|}{ Adolescent-onset schizophrenia } \\
\hline \multirow[t]{2}{*}{ VBR } & Patients & 9 & 8.22 & \pm 2.68 & $24(0.145)$ \\
\hline & Controls & 9 & 5.64 & \pm 3.83 & \\
\hline \multirow[t]{2}{*}{ PFAI } & Patients & 9 & 3.25 & \pm 2.01 & $37(0.757)$ \\
\hline & Controls & 9 & 3.26 & \pm 1.32 & \\
\hline
\end{tabular}

VBR, ventricle to brain ratio; PFAl, pre-frontal sulcal prominence index; $U$, Mann-Whitney test; $p$, signifance. 
Table 3. Correlation coefficients values (Spearman's rho) between demographic variables, psychopathology, and neuroimaging parameters of the whole sample.

\begin{tabular}{|c|c|c|c|c|c|c|c|c|}
\hline & Age & $\begin{array}{l}\text { Age of } \\
\text { onset }\end{array}$ & Duration & $\begin{array}{l}\text { Positive } \\
\text { symptoms }\end{array}$ & $\begin{array}{l}\text { Negative } \\
\text { symptoms }\end{array}$ & $\begin{array}{l}\text { Desorganization } \\
\text { symptoms }\end{array}$ & PFAI & VBR \\
\hline \multicolumn{9}{|l|}{ Age } \\
\hline Age of onset & $0.82 * *$ & & & & & & & \\
\hline Duration & 0.24 & -0.26 & & & & & & \\
\hline Positive symptoms & $0.85^{*}$ & 0.72 & -0.01 & & & & & \\
\hline Negative symptoms & -0.53 & -0.32 & -0.07 & -0.70 & & & & \\
\hline Desorganization symptoms & -0.69 & -0.63 & 0.21 & $-0.79 *$ & $0.84 *$ & & & \\
\hline PFAI & 0.31 & 0.35 & -0.07 & 0.46 & -0.14 & -0.34 & & \\
\hline VBR & 0.07 & 0.07 & -0.13 & 0.005 & 0.50 & 0.10 & 0.26 & \\
\hline
\end{tabular}

VBR, ventricle to brain ratio; PFAl, pre-frontal sulcal prominence index.

Correlation coefficients that reached significance are displayed in bold. *The level of significance $(p<0.01)$ was obtained after Bonferroni adjustment $(0.05 / 64=0.0008)$.

groups in terms of age and gender $(p=0.26$, and $p=$ 0.23 , respectively).

Both subjects and controls showed no significant differences in terms of age $[9.83 \pm 1.47$, and $9.83 \pm 0.41$, respectively, in the children group (CG)]; and [14.89 \pm 0.78 , and $16.11 \pm 1.05$, respectively, in the adolescents group (AG)]. The age of onset of the disorder was $5 \pm$ 0.84 years in the $C G$, and $13 \pm 0.53$ years in the $A G$.

Reliability rates, measured by the Intraclass Correlation Coefficient, were $0.70(p=0.01)$ for PFAl, and $0.90(p=0.001)$ for VBR. Table 1 shows that VBR of the patients group showed a significant difference when compared with controls. There were no significant differences in terms of PFAl. Table 2 shows PFAI and VBR values when the whole sample was dichotomized in two subgroups i.e. children and adolescent onset schizophrenia.

The matrix correlation coefficient between age, age of onset of the disorder, duration, psychopathology and neuroimaging parameters, for the whole sample, showed a positive correlation between age and positive symptoms, positive symptoms and age of onset of the disorder, and a negative correlation between age and disorganization, and age and negative symptoms. However, despite the high value of such correlations they didn't achieve significance, due to the stringency of Bonferroni correction (level of significance after correction (0.0008) (0.05/64) (Table 3).

The correlations between VBR and psychopathology parameters showed no significance. Significant correlations were found between positive symptoms and age, while disorganization symptom correlated negatively with positive symptoms and positively with negative symptoms.

\section{DISCUSSION}

The main finding of the present study is that patients with early-onset schizophrenia have significantly higher degrees of ventricular enlargement when compared with controls. Differences in the morphology of ventricles between adult patients with schizophrenia, and normal controls have been consistently reported in the literature ${ }^{7}$, and also well documented in child neuroimaging studies 5,12,13.

In the present study, the absence of a correlation between ventricular enlargement and duration of illness lends weight to the argument that ventricular enlargement is not progressive and antedates the onset of the disorder ${ }^{12}$. Ventricular enlargement is shown to be present early in the course of schizophrenia, as assessed both by CT scans ${ }^{12}$ as well as MRI ${ }^{28}$. The stable dimensions of ventricles both in chronic and around the onset of the disease also support the neurodevelopmental nature of brain morphology in schizophrenia ${ }^{29}$.

As emphasized by Hendren et al. ${ }^{30}$ some studies have shown a non progression of ventricular enlargement while others showed opposite findings as it is the case of Rapoport et al. ${ }^{5}$, who using MRI, observed progressive ventricular enlargement when children with schizophrenia were scanned within an interval of two years. In the present study, the neuroimaging parameters were not significantly correlated with psychopathological symptoms. However, the age of 
onset of the disorder was positively correlated with positive symptoms, and negatively correlated with disorganization symptoms. Such findings may be explained by the fact that negative symptoms are more enduring whereas positive symptoms are more transient ${ }^{31}$.

The present study have some strengths, such as the use of a very accurate PFA evaluation, planimetric measures of the ventricles (VBR), both evaluated by two raters who achieved a good reliability. Previous $C T$ scan studies ${ }^{12,13}$ used the standard planimetric measures to evaluate ventricular enlargement but Badura et al. ${ }^{14}$ used linear indexes for the measurement of the liquor spaces, claiming that they are more accurate than the VBR. However, examining Badura's et al. study we found that only the "Huckman number", which is a measure of the ventricles at the anterior horns level, had a modest significant difference (0.04) between patients and controls in children with very early onset of schizophrenia but not with the early onset group. Additionally the results of the present study are not in line with the findings of Badura et al. ${ }^{14}$ since we found no evidence that splitting the sample in early age of onset and very early age of onset schizophrenia have enhanced the differences between patients and controls in terms of ventricular enlargement.

Limitations of this study included a small sample, especially when such small sample was split in two distinct populations - children and adolescents - due to the fact that is known that such procedure leads to a decrease in the statistical power to detect differences among populations. Another limitation was the precise determination of the age of onset of the disorder due to the fact that it is well known that many children have behavioral changes that are not considered pathological by their families until they are evaluated by a mental health professional. This may be due to the fact that, as previously mentioned, some studies have shown that in childhood onset schizophrenia negative symptoms have an insidious onset beginning in early ages and run almost unnoticed, whereas psychotic symptoms appear later, thus being more identifiable ${ }^{31}$. A further important limitation is that neuroimaging studies were performed with CT scans a technique that it is known to be the most available and feasible, but which can provide less detail of the brain structure, when compared with MRI. As happens in any mental disorder, the diagnosis of schizophrenia is essentially clinical, but CT scans can be included in the armamentarium of the assessment of children suspected of having psychotic symptoms, providing valuable clinical data for early detection and treatment decisions.

In conclusion, in the present study we have replicated the finding of a significant enlargement of brain ventricles in a group of patients with EOS schizophrenia, when compared with controls. The ventricle enlargement did not correlate with age of onset of the disorder suggesting that such abnormality is not progressive. The comparisons of both subgroups have shown no significant differences in terms of their ventricles sizes. Our results suggest that ventricle enlargement can be present from the onset of the disorder lending further weight to the neurodevelopmental hypothesis of schizophrenia.

Acknowledgments - Dr Nelio Garcia de Barros and the Division of Neuroadiology of Hospital das Clinicas for providing technical support for the study.

\section{REFERENCES}

1. American Psychiatric Association. Diagnostic and statistic manual for mental disorders, $4^{\text {th }}$ Edition. Washington (DC): APA, 1996.

2. World Health Organization. International classification of disorders, $10^{\text {th }}$ Edition. New York (NY): WHO, 1993.

3. Kraeplin E. Dementia praecox. Livingstone: Edinburg E\&S, 1919.

4. Burd L, Kerbeshian J. A North Dakota prevalence study of schizophrenia presenting in childhood. J Am Acad Child Adol Psychiatry 1987;26:347-350.

5. Rapoport JL, Giedd J, Jacobsen L, et al. Childhood-onset schizophrenia: progressive ventricular change during adolescence. Arch Gen Psychiatry 1997;54:897-903.

6. Beitchman JH. Childhood onset schizophrenia: a review and comparison with adult-onset schizophrenia. Psychiat Clin N Am 1985;8:793814.

7. Weinberger DR. From neuropathology to neurodevelopment. Lancet 1995;346:552-557.

8. Green WH, Gayol M, Hardesty A, Bassiri M. Schizophrenia with childhood onset: a phenomenological study of 38 cases. J Am Acad Child Adolesc 1992;31:968-976.

9. Alaghband-Rad J, Mckenna K, Gordon CT, et al. Childhood-onset schizophrenia: the severity of premorbid course. J Am Acad Child Adolesc Psychiatry 1995;34:1273-1283.

10. Gordon CT, Fraizer JA, Mckenna K, Giedd J, Zametkin A, Zahn T et al. Childhood-onset schizophrenia: an NIMH study in progress. SchizophrBull 1994;20:697-712.

11. Elkis H, Friedman L, Wise A, Meltzer HY. Meta-analyses of studies of ventricular enlargement and cortical sulcal prominence in mood disorders. Arch Gen Psychiatry 1995;52:735-746.

12. Schulz SC, Koller MM, Kishore PR, Hamer RM, Gehl JJ, Friedel RO. Ventricular enlargement in teenage patients with schizophrenia spectrum disorder. Am J Psychiatry 1983;140:1592-1595

13. Reiss D, Feinstein C, Weinberger DR, King R, Wyatt RJ, Brallier D. Ventricular enlargement in child psychiatric patients: a controlled study with planimetric measurements. Am J Psychiatry 1983;140:453-456.

14. Badura F, Trott GE, Mehler-Wex C, et al. A study of cranial computer tomogramas in very early and early onset schizophrenia. J Neural Transmission 2001;108:1335-1344.

15. Rapoport JL. Addington AM, Frangou S and MRC Psych- The neurodevelopmental model of schizophrenia: update 2005. Molecular Psychiatry 2005;10:434-449.

16. Liddle PF, Barnes TRE, Morris D, Haque S. The syndromes of chronic schizophrenia. Br J Psychiatry 1989;157:119-122. 
17. Elkis H, Kimura L, Nita LM, Tissot MCRG. Neuroimagem estrutural e psicopatologia: sintomas positivos e negativos e dilatação ventricular na esquizofrenia. Rev Bras Psiq 2001;23(Supl 1):19-23.

18. Weinberger DR. Implication of normal brain development for the pathogenesis of schizophrenia. Arch Gen Psychiatry 1987;44:660-669.

19. Lewis SW. Computerised tomography in schizoprenia 15 years on. $\mathrm{Br}$ J Psychiatry 1990;157:16-24.

20. American Psychiatric Association. Diagnostic and statistic manual for mental disorders, $3^{\text {rd }}$ Edition, revised. Washington (DC): APA, 1987.

21. Puig-Antich J, Chambers W. The schedule for affective disorders and schizophrenia for school-age children (Kiddies-SADS). New York: New York State Psychiatric Association, 1988.

22. Orvaschel H, Puig-Antich J. Schedule for affective disorders and schizophrenia for school-age children: epidemiologic version, Medical College of Pennsylvania. Eastern Pennsylvania Psychiatric Institute, 1987.

23. Synek V, Reuben JR. The ventricular-brain ratio using planimetric measurement of EMI scans. Brit J Psychiatry 1976;49:233-237.

24. Shelton RC, Karson CN, Doram AR, Pickar D, Bigelow LB, Winberger DR. Cerebral structural pathology in schizophrenia: evidence for a selective prefrontal cortical defect. Am J Psychiat 1986;145:154-163.
25. Friedman L, Knutson L, Shurell M, Meltzer H. Prefrontal sulcal prominence is inversely related to response to clozapine in schizophrenia. Biol Psychiatry 1991;29:865-877.

26. Elkis H, Friedman L, Buckley PF, et al. Increased prefrontal sulcal prominence in relatively young patients with unipolar major depression. Psychiat Res Neuroimaging 1996;67:123-124.

27. Bartko J, Carpenter W. On methods and theory of reliability. J Nerv Ment Dis 1976;163:307-317.

28. Sowell ER, Levitt J, Thompson PM, et al. Brain abnormalities in earlyonset schizophrenia spectrum disorder, observed with statistical parametric mapping of structural magnetic resonance images. Am J Psychiatry 2000;157:1475-1484

29. Vita A, Dieci M, Giobbio GM, Tenconi F, Invernizzi G. Time course of cerebral ventricular enlargement in schizophrenia supports the hypothesis of its neurodevelopmental nature. Schizophr Res 1997;23:25-30.

30. Hendren RL, DeBacker I, Pandina GJ. Review of neuroimaging studies of child and adolescent psychiatric disorders from the past 10 years. J Am Acad Child Adolesc Psychiatry 2000;39:815-827.

31. Bettes BA, Walker E. Positive and negative symptoms in psychotic and other psychiatrically disturbed children. J Child Psychol Psychiatry 1987;28:565-568. 